\title{
COVID-19 vaccine acceptance among pregnant women and mothers of young children: results of a survey in 16 countries
}

\author{
Malia Skjefte ${ }^{1}$ Michelle Ngirbabul ${ }^{1}$. Oluwasefunmi Akeju ${ }^{2}$. Daniel Escudero ${ }^{2}$. Sonia Hernandez-Diaz ${ }^{2}$. \\ Diego F. Wyszynski ${ }^{3}$. Julia W. Wu ${ }^{2}$
}

Received: 2 February 2021 / Accepted: 5 February 2021 / Published online: 1 March 2021

(c) The Author(s) 2021

\begin{abstract}
With the development of multiple effective vaccines, reducing the global morbidity and mortality of COVID-19 will depend on the distribution and acceptance of COVID-19 vaccination. Estimates of global vaccine acceptance among pregnant women and mothers of young children are yet unknown. An understanding of the challenges and correlates to vaccine acceptance will aid the acceleration of vaccine administration within these populations. Acceptance of COVID-19 vaccination among pregnant women and mothers of children younger than 18-years-old, as well as potential predictors, were assessed through an online survey, administered by Pregistry between October 28 and November 18, 2020. 17,871 total survey responses from 16 countries were obtained. Given a 90\% COVID-19 vaccine efficacy, 52.0\% of pregnant women $(\mathrm{n}=2747 / 5282)$ and $73.4 \%$ of non-pregnant women $(n=9214 / 12,562)$ indicated an intention to receive the vaccine. $69.2 \%$ of women $(n=11,800 / 17,054)$, both pregnant and non-pregnant, indicated an intention to vaccinate their children. Vaccine acceptance was generally highest in India, the Philippines, and all sampled countries in Latin America; it was lowest in Russia, the United States and Australia. The strongest predictors of vaccine acceptance included confidence in vaccine safety or effectiveness, worrying about COVID-19, belief in the importance of vaccines to their own country, compliance to mask guidelines, trust of public health agencies/health science, as well as attitudes towards routine vaccines. COVID-19 vaccine acceptance and its predictors among women vary globally. Vaccination campaigns for women and children should be specific for each country in order to attain the largest impact.
\end{abstract}

Keywords Vaccine acceptance $\cdot$ Vaccine confidence $\cdot$ COVID-19 $\cdot$ Pregnancy $\cdot$ Vaccination

$\begin{array}{ll}\text { Abbreviations } & \\ \text { COVID-19 } & \text { Coronavirus disease 2019 } \\ \text { IRCEP } & \begin{array}{l}\text { International registry of coronavirus expo- } \\ \text { sure in pregnancy }\end{array} \\ \text { GED } & \begin{array}{l}\text { General equivalent degree } \\ \text { HCP }\end{array} \\ \text { Health care provider } \\ \text { mRV } & \text { Human papillomavirus } \\ \text { SARS-CoV-2 } & \begin{array}{l}\text { Messenger ribonucleic acid } \\ \text { Severe acute respiratory syndrome corona- } \\ \text { virus } 2 \beta\end{array}\end{array}$

Julia W. Wu

wwu@hsph.harvard.edu

1 Department of Global Health and Population, Harvard TH Chan School of Public Health, Boston, MA, USA

2 Department of Epidemiology, Harvard TH Chan School of Public Health, Boston, MA, USA

3 Pregistry, Los Angeles, CA, USA

$\begin{array}{ll}\text { UK } & \text { United Kingdom } \\ \text { US } & \text { United States of America } \\ \text { WHO } & \text { World Health Organization }\end{array}$

\section{Background}

As we reach the one-year anniversary of the Severe Acute Respiratory Syndrome Coronavirus 2 (SARS-CoV-2) pandemic, the devastating impacts of this infectious disease outbreak on society are clear. By the end of 2020, the total number of Coronavirus Disease 2019 (COVID-19) cases reached more than 80 million worldwide, and the number of deaths from COVID-19 related causes hit 1.8 million [1]. Along with the loss of human life, the pandemic has led to unprecedented public health challenges, stressing health care systems, disrupting supply chains and economies, and prompting a mental health crisis [2, 3]. Simultaneously, several COVID-19 vaccines have been developed and approved 
at an unprecedented speed, while holding rigorous regulatory processes [4-6]. These vaccines, however, cannot curb the epidemic without widespread acceptance. Assuming a basic reproductive number of 4 , the community immunity level needs to reach at least $75 \%$ to stop the COVID-19 pandemic. Therefore, we must consider vaccine delivery strategies and determine the vaccine acceptance needed for society to return to pre-pandemic conditions [7]. The World Health Organization (WHO) has listed vaccine hesitancy, defined as the delay in acceptance or refusal of vaccines, as one of the top ten threats to global health, even prior to the current COVID-19 pandemic [8, 9]. Early COVID-19 vaccine surveys on vaccine acceptance foreshadow global challenges to COVID-19 vaccine distribution [10-12].

The COVID-19 vaccine trials generated very limited data on safety and efficacy for pregnant women and children. Yet, pregnant women with symptomatic COVID-19 might be at an increased risk for severe illness than non-pregnant peers; and children appear to have a lower risk for symptomatic COVID-19 but similar rates of infection, making them potential transmitters of the virus [13-19]. Since mothers are often key decision-makers for whether their children will receive vaccinations, it is important to measure vaccine confidence among mothers of young children, and to investigate the predictors for their vaccine acceptance or reluctance, in order to prepare for COVID-19 vaccination efforts. In this study, we describe the level of acceptance, attitudes surrounding the COVID-19 vaccine and key predictors of COVID-19 vaccine acceptance among pregnant women and mothers of young children in 16 countries.

\section{Methods}

\section{Study design and data collection}

An anonymous, online, cross-sectional survey was conducted in 16 countries between October 28 and November 18, 2020, to assess the COVID-19 vaccine acceptance level and potential predictors among pregnant women and mothers of young children for themselves and for their children. Predictors examined included COVID-19 vaccine confidence, negative experiences with COVID-19, perception on the risk and seriousness of COVID-19, public trust, general vaccine attitude, demographics and socioeconomic status. This survey included women aged 18 years or older, currently pregnant or with at least one child under 18 years of age. All potential participants were informed of the research objectives as well as the standards of data confidentiality. Fourteen countries with high cumulative incidences of COVID-19 as of Oct 28, 2020 were included, with their ranking: the United States (US), India, Brazil, Russia, Spain, Argentina, Colombia, UK, Mexico, Peru, South Africa, Italy, Chile and the Philippines. Additionally, Australia and New Zealand were included for reference given that they had lower incidences of COVID-19 (Fig. 1). The survey was hosted on the Pregistry platform for COVID-19 studies and advertised predominantly on social media platforms and online parenting forums [20]. The advertisements and survey were available in six languages (English, French, Italian, Portuguese, Russian, and Spanish). Interested participants were invited to follow a link to take the survey. Additional details on the survey structure can be found in the supplemental materials.

\section{Definition of COVID-19 vaccine acceptance}

To measure vaccine acceptance among three groups (pregnant women, non-pregnant women and children), three separate questions were used. Each question followed a general format "If a COVID-19 vaccine were safe and available to (you/your child/children) for free, how likely would (you/ your child/children) be to get vaccinated (during pregnancy) if the vaccine has an efficacy of [90\% (in other words, it reduces the chance of getting infected by 90\%)?]. The first two questions regarding self-vaccination could only be answered by pregnant women and non-pregnant women, respectively. The third question regarding child-vaccination was open to all women. For each question, responses were recorded on a five-point Likert scale ('very likely', 'fairly likely', 'somewhat likely', 'quite unlikely' and 'not at all likely'). Vaccine acceptance was defined as yes if a respondent answered, 'very likely', 'fairly likely' or 'somewhat likely', and no for any other responses.

\section{Statistical analysis}

We tabulated the distribution of the COVID-19 vaccine acceptance responses against questions from the predictor sections. Denominators vary slightly due to missingness in participant responses. We ran univariate logistic regressions to identify potential predictors of women's COVID-19 vaccine acceptance/reluctance across countries. Strongest predictors as well as key demographic factors were included in the multivariate regression models. The area under the receiver operating characteristic (ROC) curve (AUC) was used to assess models' prediction capacity. We further examined differences in attitudes and acceptance between countries and repeated the prediction models within countries.

\section{Findings}

\section{Study participants}

Among 17,871 respondents, $29.6 \%(n=5294)$ were pregnant at the time of taking the survey. Among pregnant women, 


\section{Participants by Country}

Total number of submissions: 17871 (Currently Pregnant: 5294-29.6\%, Currently not pregnant: 12571-70.4\%)

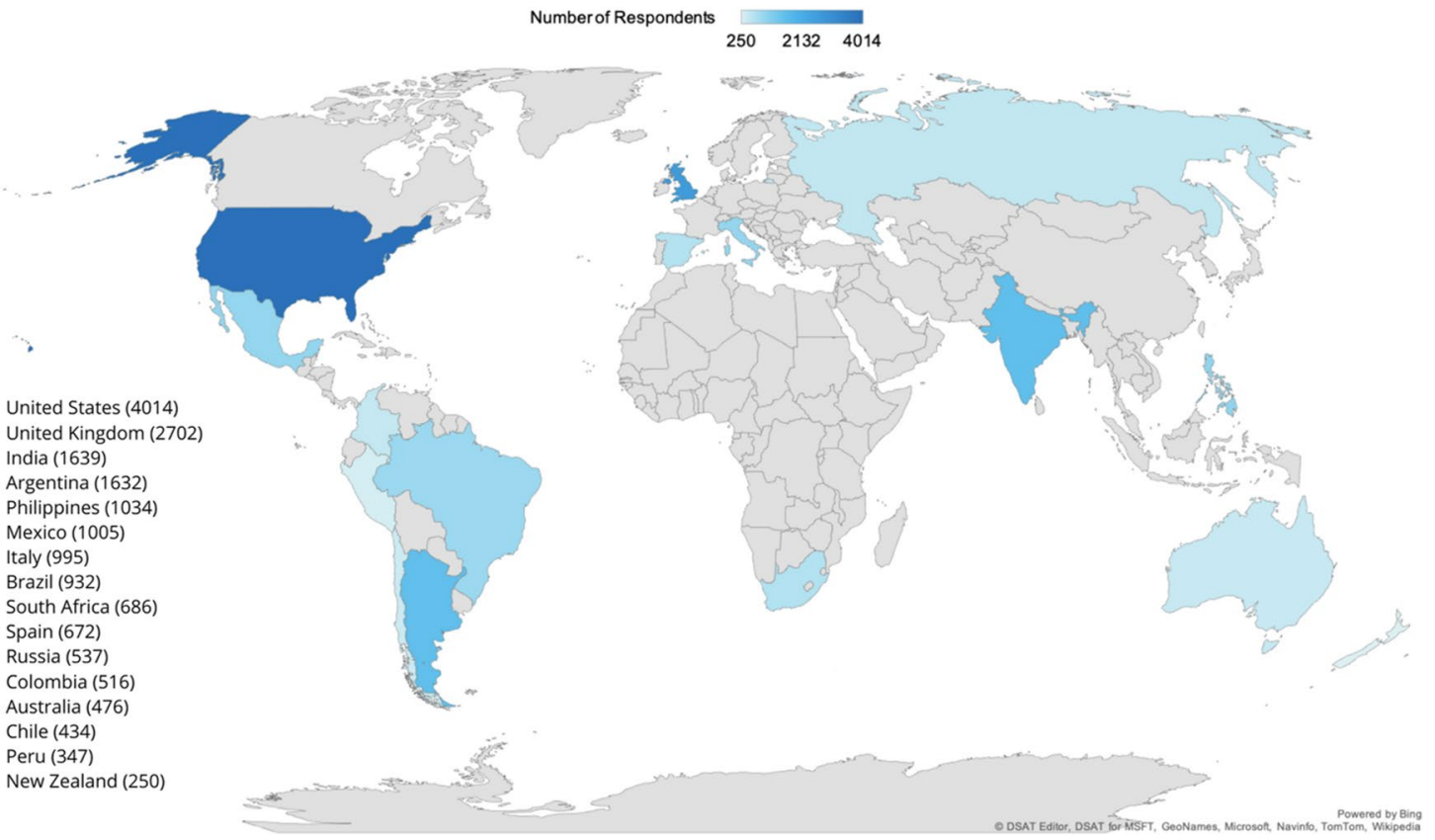

Fig. 1 Enrollment occurred in the 14 most-affected countries during Oct 28-Nov 18, 2020, through an online pregnant women and mothers' social media community, Pregistry. New Zealand and Australia were included as reference countries

$49.7 \%(n=2629)$ had at least one child (Table 1). For those who were pregnant, the mean gestational age was 20.0 weeks $(\mathrm{SD}=9.4)$. The mean age of all respondents, both pregnant and non-pregnant, was 34.4 years $(\mathrm{SD}=7.3)$. A summary of respondent demographics is included in Table 1. Countryspecific demographics are summarized in Table 1S. Overall distributions of age were homogenous across countries. India, Italy, Australia and New Zealand had higher than overall proportions of high-income respondents; US, South Africa, UK, India, Australia and New Zealand had higher than overall proportions of highly educated respondents; US, Russia and India had higher than overall proportions of married respondents.

\section{Global vaccine acceptance and confidence}

Among pregnant women, 52.0\% $(\mathrm{n}=2747)$ intended to receive COVID-19 vaccination during their pregnancy if an efficacy of $90 \%$ were achieved. Responses among pregnant women varied substantially by country (range: 28.8-84.4\%). COVID-19 vaccine acceptance level was above $80 \%$ for pregnant women in Mexico and India; and below $45 \%$ for US, Australia and Russia (Fig. 2a). Among non-pregnant women, $73.4 \%(n=9214 / 12,562)$ intended to receive vaccination. COVID-19 vaccine acceptance among non-pregnant women also varied substantially between countries (range 48.6-93.1\%). COVID-19 vaccine acceptance level was above $90 \%$ for non-pregnant mothers in India, Brazil and Mexico; and below 56\% for Australia, US and Russia (Fig. 2b). Among the 17,054 women who stated their likelihood to vaccinate their children, results were very similar. COVID-19 vaccine acceptance levels among mothers for their children was above $85 \%$ in India, Mexico, Brazil and Colombia; and below 52\% for Australia, US and Russia (Fig. 2c). This country-variable pattern persisted after standardizing for key demographics including age, education, income and marital status.

Overall, $53.0 \%$ of women were confident that a nationally approved COVID-19 vaccine would be safe, with no harmful side effects (Fig. 3a), and 60.4\% were confident that such a vaccine would be effective, protecting most people who receive the vaccine (Fig. $3 b$ ).

\section{Perceptions on the COVID-19 pandemic}

The perceived seriousness of COVID-19 and importance of prevention measures were also highly variable among the 16 sampled countries, and it did not correspond to the infection rate in the country. Women's level of worry about COVID-19 in the US and Russia was comparable 
Table 1 Baseline characteristics among pregnant women and mothers of young children $(n=17,871)$

\begin{tabular}{|c|c|c|c|c|c|c|c|}
\hline \multirow{3}{*}{$\begin{array}{l}\text { Vaccine acceptance among } \\
\text { core demographic groups }\end{array}$} & \multirow{3}{*}{$\begin{array}{l}\text { All respondents } N=17,871 \\
(100) \\
\text { Total frequency ( } \% \text { of } \\
\text { sample) }\end{array}$} & \multicolumn{4}{|c|}{ Accept for themselves } & \multirow{2}{*}{\multicolumn{2}{|c|}{$\begin{array}{l}\text { Accept for child/children } \\
\text { Women who indicated } \\
\text { whether or not they would } \\
\text { vaccinate their child/chil- } \\
\text { dren } \mathrm{N}=17,054\end{array}$}} \\
\hline & & \multicolumn{2}{|c|}{$\begin{array}{l}\text { Pregnant women } \\
\mathrm{N}=5282\end{array}$} & \multicolumn{2}{|c|}{$\begin{array}{l}\text { Non-pregnant mothers } \\
\mathrm{N}=12,562\end{array}$} & & \\
\hline & & All N (\%) & $\begin{array}{l}\text { Accepted } \\
\text { vaccine N } \\
(\%)\end{array}$ & All N (\%) & $\begin{array}{l}\text { Accepted } \\
\text { vaccine N } \\
(\%)\end{array}$ & All N (\%) & $\begin{array}{l}\text { Accepted } \\
\text { vaccine N } \\
(\%)\end{array}$ \\
\hline \multicolumn{8}{|l|}{ No. children } \\
\hline None & $2661(14.9)$ & $2658(50.3)$ & $1488(56.0)$ & NA & NA & $1916(11.2)$ & $1416(73.9)$ \\
\hline One child & $6795(38.1)$ & $1735(32.9)$ & $906(52.2)$ & $5054(40.2)$ & $3957(78.3)$ & $6765(39.7)$ & $4878(72.1)$ \\
\hline Two children & 5465 (30.6) & $594(11.3)$ & $249(41.9)$ & $4868(38.8)$ & $3599(73.9)$ & $5448(32.0)$ & $3785(69.5)$ \\
\hline At least 3 children & $2938(16.5)$ & $295(5.6)$ & $104(35.3)$ & $2640(21.0)$ & $1658(62.8)$ & $2925(17.2)$ & $1721(58.8)$ \\
\hline \multicolumn{8}{|l|}{ Age (years) } \\
\hline $18-24$ & $1299(7.3)$ & $674(12.8)$ & $331(49.1)$ & $625(5.0)$ & $415(66.4)$ & $1175(6.9)$ & $716(60.9)$ \\
\hline $25-29$ & $3396(19.0)$ & $1566(29.7)$ & $807(51.5)$ & $1827(14.5)$ & $1287(70.4)$ & $3118(18.3)$ & $2050(65.8)$ \\
\hline $30-34$ & 4937 (27.6) & $1911(36.2)$ & $1010(52.9)$ & $3021(24.1)$ & $2235(74.0)$ & $4680(27.4)$ & $3254(69.6)$ \\
\hline $35-39$ & $4041(22.6)$ & $983(18.6)$ & $518(52.7)$ & $3054(24.3)$ & $2247(73.6)$ & $3929(23.0)$ & $2749(70.0)$ \\
\hline $40-65$ & $4189(23.5)$ & $148(2.8)$ & $81(54.7)$ & $4035(32.1)$ & $3030(75.1)$ & $4152(24.4)$ & $3031(73.0)$ \\
\hline \multicolumn{8}{|l|}{ Socioeconomic status } \\
\hline Poor & $1993(11.2)$ & $444(8.4)$ & $249(56.1)$ & $1548(12.3)$ & $1054(68.1)$ & $1944(11.4)$ & $1264(65.0)$ \\
\hline Lower-middle class & $5224(29.3)$ & $1386(26.2)$ & $727(52.5)$ & $3835(30.5)$ & $2757(71.9)$ & $5027(29.5)$ & $3446(68.6)$ \\
\hline Middle class & $8061(45.2)$ & $2553(48.3)$ & $1295(50.7)$ & $5505(43.8)$ & $4107(74.6)$ & $7662(44.9)$ & $5345(69.8)$ \\
\hline $\begin{array}{l}\text { Upper-middle class or } \\
\text { wealthy }\end{array}$ & $2573(14.4)$ & $899(17.0)$ & $476(53.0)$ & $1674(13.3)$ & $1296(77.4)$ & $2421(14.2)$ & $1745(72.1)$ \\
\hline \multicolumn{8}{|l|}{ Education } \\
\hline Never attended high school & $1098(6.2)$ & $239(4.5)$ & $104(43.5)$ & $859(6.9)$ & $614(71.5)$ & $1074(6.3)$ & $698(65.0)$ \\
\hline High school or GED & $2114(11.9)$ & $469(8.9)$ & $263(56.1)$ & $1644(13.1)$ & $1151(70.0)$ & $2061(12.1)$ & $1382(67.1)$ \\
\hline Some College or University & $3159(17.7)$ & $867(16.4)$ & $422(48.7)$ & $2289(18.3)$ & $1575(68.8)$ & $3052(17.9)$ & $1964(64.4)$ \\
\hline $\begin{array}{l}\text { College Diploma or Uni- } \\
\text { versity Degree }\end{array}$ & $6746(37.9)$ & $2164(41.0)$ & $1092(50.5)$ & $4579(36.5)$ & $3304(72.2)$ & $6386(37.5)$ & $4337(67.9)$ \\
\hline $\begin{array}{l}\text { Master's, Professional or } \\
\text { Doctoral Degree }\end{array}$ & $4703(26.4)$ & $1534(29.1)$ & $862(56.2)$ & $3167(25.3)$ & $2558(80.8)$ & $4450(26.1)$ & $3403(76.5)$ \\
\hline \multicolumn{8}{|l|}{ Health insurance status } \\
\hline Insured & $13,737(77.0)$ & $4416(83.6)$ & $2284(51.7)$ & $9319(74.2)$ & $6888(73.9)$ & $13,050(76.5)$ & $9090(69.7)$ \\
\hline Not insured & $4111(23.0)$ & $866(16.4)$ & $263(53.5)$ & $3243(25.8)$ & $2326(71.7)$ & $4004(23.5)$ & $2710(67.7)$ \\
\hline \multicolumn{8}{|l|}{ Marital status } \\
\hline Married & $12,004(67.4)$ & $3762(71.4)$ & $1934(51.4)$ & $8236(65.8)$ & $6094(74.0)$ & $11,456(67.4)$ & $7955(69.4)$ \\
\hline All unmarried & $5797(32.6)$ & $1505(28.6)$ & $806(53.6)$ & $4288(32.2)$ & $3095(72.1)$ & $5546(32.6)$ & $3816(68.8)$ \\
\hline Living with a partner & $3195(18.0)$ & $1031(19.6)$ & $580(56.3)$ & $2162(17.3)$ & $1623(75.1)$ & $3026(17.8)$ & $2163(71.5)$ \\
\hline Never married & $1541(8.7)$ & $386(7.3)$ & $188(48.7)$ & $1154(9.2)$ & $782(67.8)$ & $1471(8.7)$ & $952(64.7)$ \\
\hline Divorced & $514(2.9)$ & $55(1.0)$ & $26(47.3)$ & $458(3.7)$ & $312(68.1)$ & $507(3.0)$ & $323(63.7)$ \\
\hline Separated & $437(2.5)$ & $27(0.5)$ & $12(44.4)$ & $410(3.3)$ & $296(72.2)$ & $342(2.5)$ & $298(69.0)$ \\
\hline Widowed & $110(0.6)$ & $6(0.1)$ & $0(0)$ & $104(0.8)$ & $82(78.9)$ & $110(0.7)$ & $80(72.7)$ \\
\hline
\end{tabular}

to that in lower incidence countries (Australia and New Zealand) (Fig. 4a). Despite this variation in concern, selfreported compliance with local mask-wearing regulations was above $75 \%$ in all countries (Fig. 4b). Most responders trusted health science in general (Figure S2a) and were satisfied with public health authorities in their countries for their performance in controlling the pandemic (Figure $\mathrm{S} 3 \mathrm{a}$ ); although the trust and satisfaction level varied among countries (Figures S2b, S3b, 5a, b). Though 74.2\% of women felt informed on the development of a COVID19 vaccine (Figure S4), 27.7\% did not follow COVID-19 
(a) COVID-19 vaccine acceptance among pregnant women $(n=5294)$ for themselves, assuming a vaccine efficacy of $90 \%$

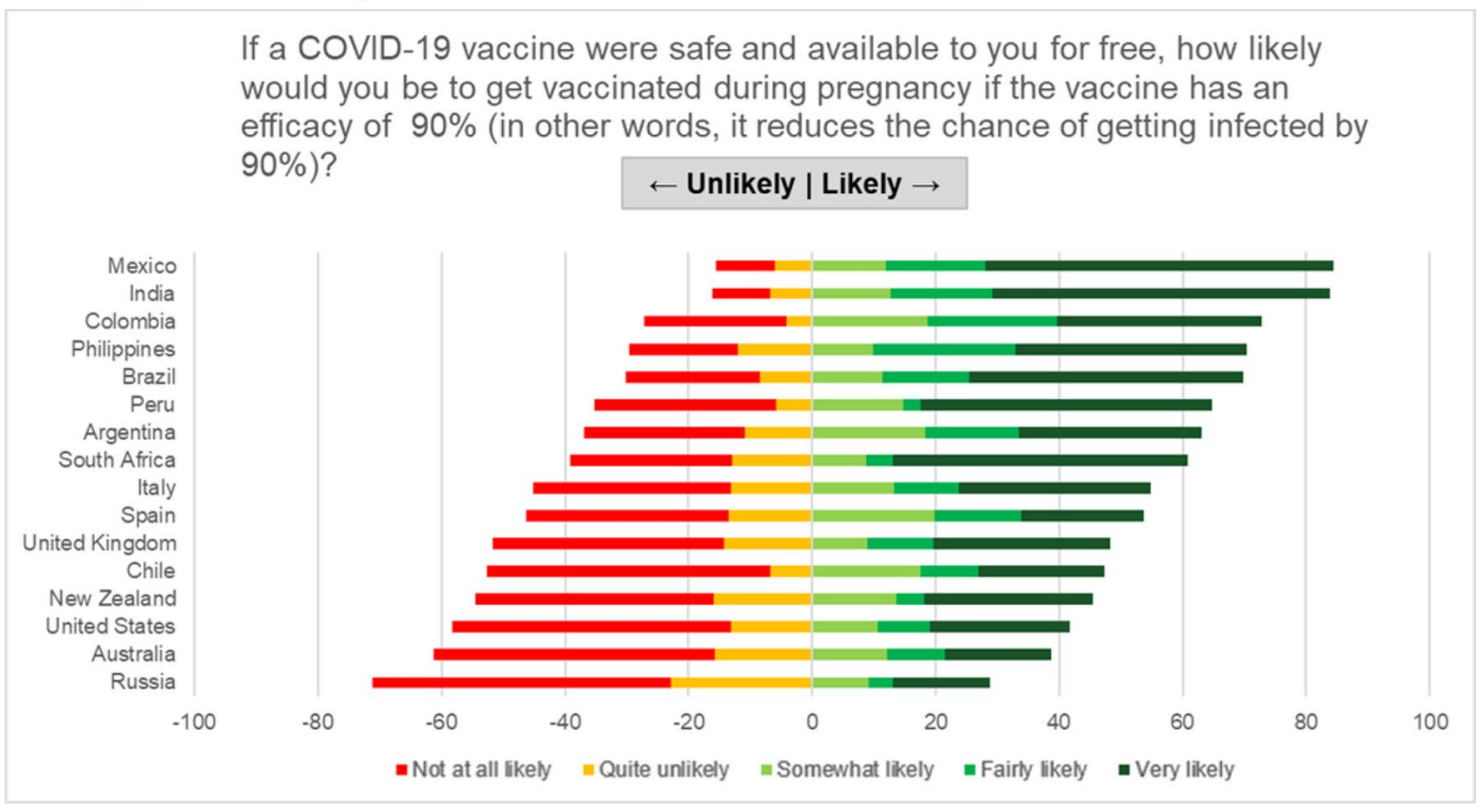

(b) COVID-19 vaccine acceptance among non-pregnant mothers $(n=12562)$ for themselves, assuming a vaccine efficacy of $90 \%$

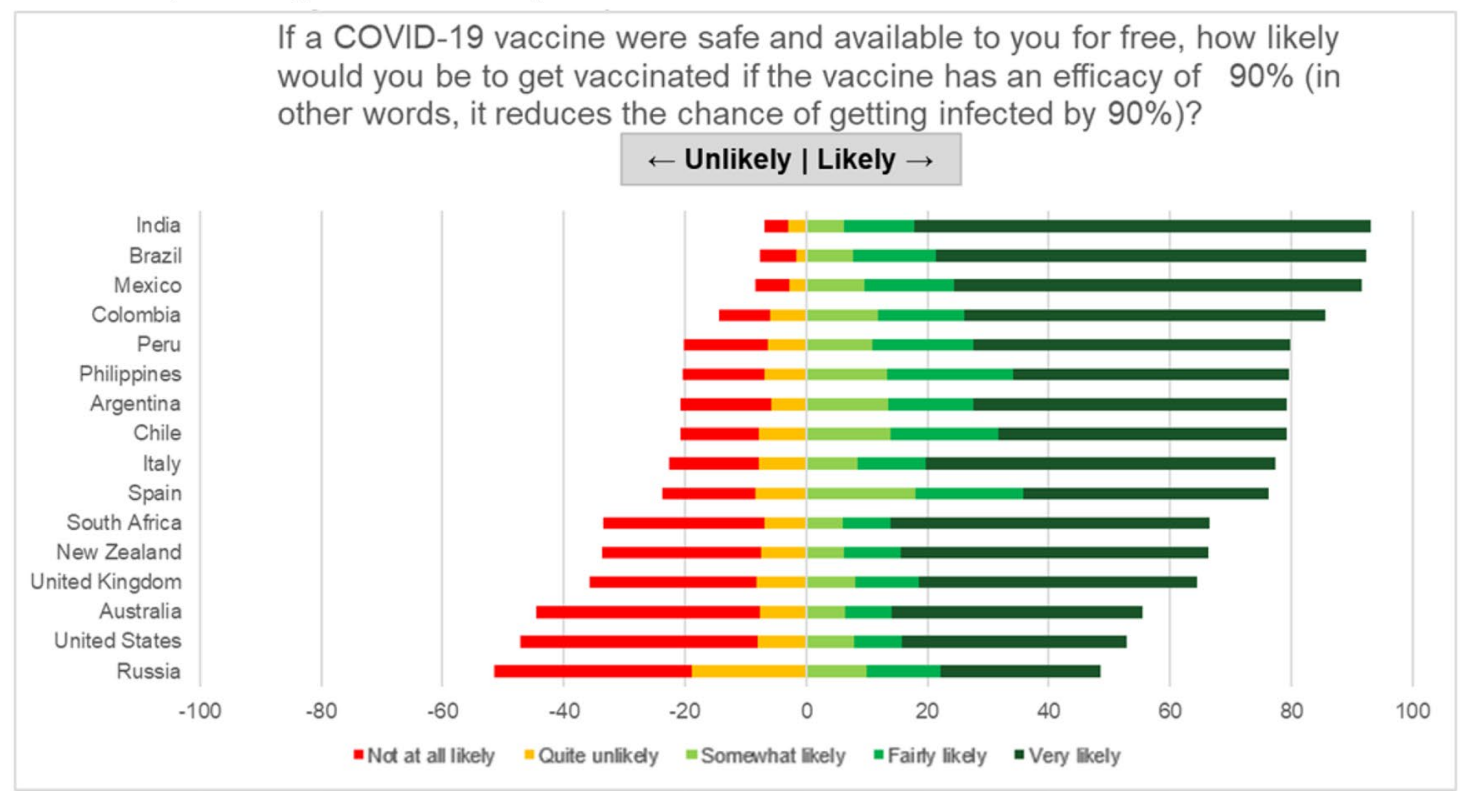

Fig. 2 COVID-19 Vaccine acceptance among pregnant women and mothers of young children. a COVID-19 vaccine acceptance among pregnant women $(n=5294)$ for themselves, assuming a vaccine efficacy of $90 \%$. b COVID-19 vaccine acceptance among non-pregnant

news in any form (TV, radio, newspaper, news websites, social media). mothers $(n=12,562)$ for themselves, assuming a vaccine efficacy of 90\%. c COVID-19 Vaccine acceptance among mothers and mothersto-be $(n=17,054)$ for their children, at an efficacy of $90 \%$

\section{Attitudes towards vaccines}

The majority of women in the 16 countries believed it was important for their own country to have a COVID19 vaccine $(85.8 \%$ ) (Figure $\mathrm{S} 1 \mathrm{a})$, and for most people in their own country to get vaccinated $(82.6 \%)$ (Figure $\mathrm{S} 1 \mathrm{~b})$. 
(c) COVID-19 Vaccine acceptance among mothers and mothers-to-be $(n=17054)$ for their children, at an efficacy of $90 \%$

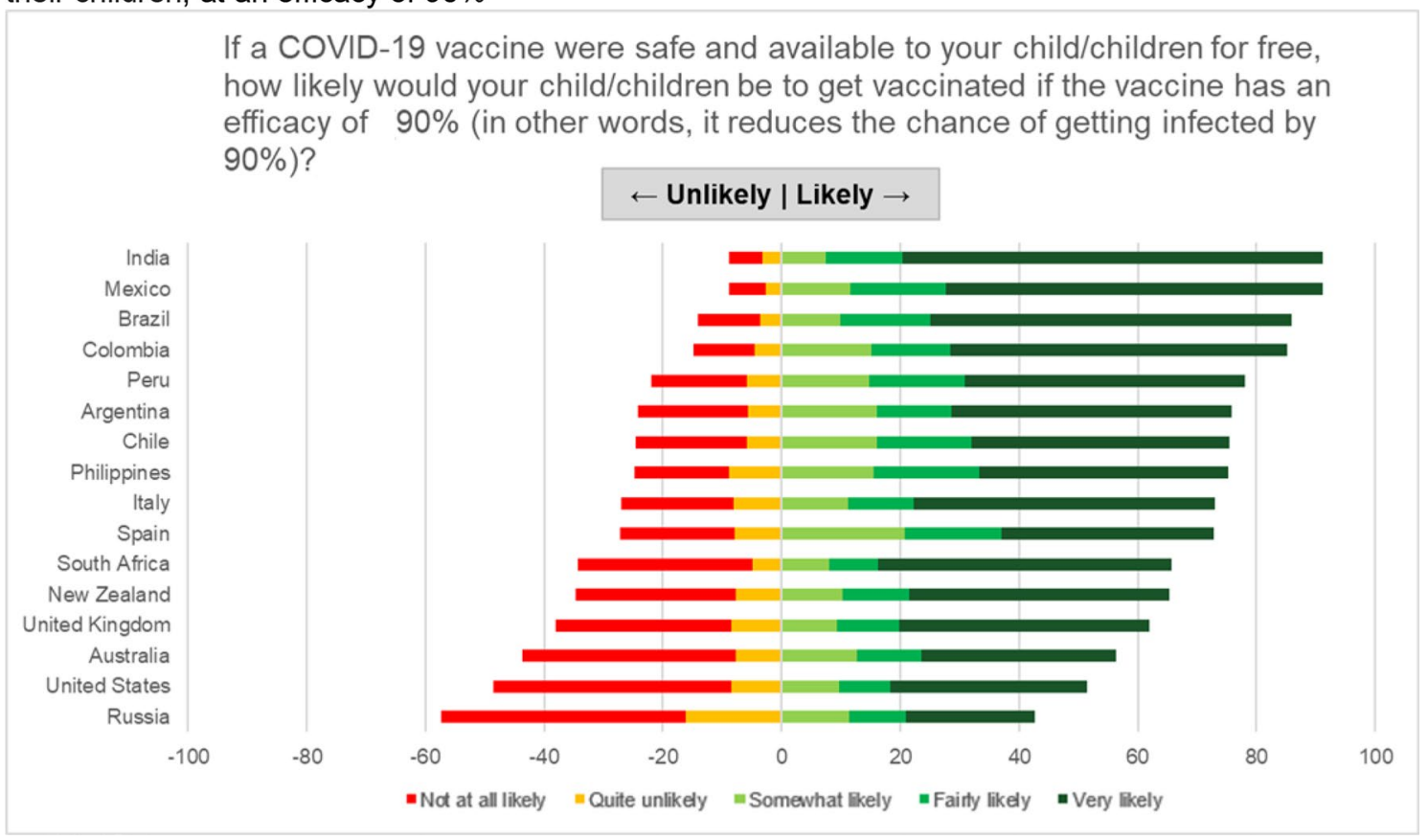

Fig. 2 (continued)

Perceptions on the importance of childhood vaccinations were also positive, with $92.0 \%$ of women responding that vaccines can protect children from serious infectious diseases (Figure S5b). In addition, $49.4 \%$, reported vaccination for influenza in the past year.

\section{Top reasons for COVID-19 vaccine reluctance}

The top three reasons for pregnant women to decline COVID-19 vaccination during pregnancy even if the vaccine were safe and free were that they did not want to expose their developing baby to any possible harmful side effects (65.9\%), were concerned that approval of the vaccine would be rushed for political reasons (44.9\%) and would like to see more safety and effectiveness data among pregnant women (48.8\%). The top reasons for mothers to be unwilling to have their child/children vaccinated for COVID-19 were that they are concerned that approval of the vaccine will be rushed for political reasons (39.8\%), would like to see more safety and effectiveness data among children (32.7\%), and believe that the vaccine is not safe and could have harmful side effects $(28.4 \%)$. Health care providers had a limited impact: only $45.9 \%$ of pregnant women and $54.6 \%$ of non-pregnant women would be more likely to have themselves/children vaccinated if recommended by health care providers.

Overall women indicated higher likelihoods to get vaccinated with higher vaccine efficacies. A sensitivity analysis was conducted to see if there was any difference in vaccine acceptance within-country before and after November $9^{\text {th }}$, 2020, the day in which Pfizer-BioNTech announced news of the first COVID-19 vaccine efficacy results. No significant difference was found in vaccine acceptance outcomes from this test.

\section{Predictors of COVID-19 vaccine acceptance}

Crude-level associations between women's COVID-19 vaccine acceptance and potential predictors are shown in Table 2. Demographic factors, such as younger age, lower income, lower education level, non-married and no health insurance were slightly linked to COVID-19 vaccine nonacceptance. Strongest predictors of COVID-19 vaccine acceptance were confidence in COVID-19 vaccine safety and efficacy, belief in the importance of vaccines/mass vaccination to their own country, confidence in routine childhood vaccines, worried about COVID-19, trust of public health agencies/health science, as well as compliance to mask guidelines (Figure S6). Although some of these determinants were correlated and their odds ratios diminished in multivariate regression models, they remained the strongest predictors (Table 3). These predictors were 
(a) Confidence that the COVID-19 vaccine approved will be safe $(n=17790)$

When a COVID-19 vaccine is approved by the public health agencies in the country where you live, how confident are you that the vaccine will be safe and with no harmful side effects?

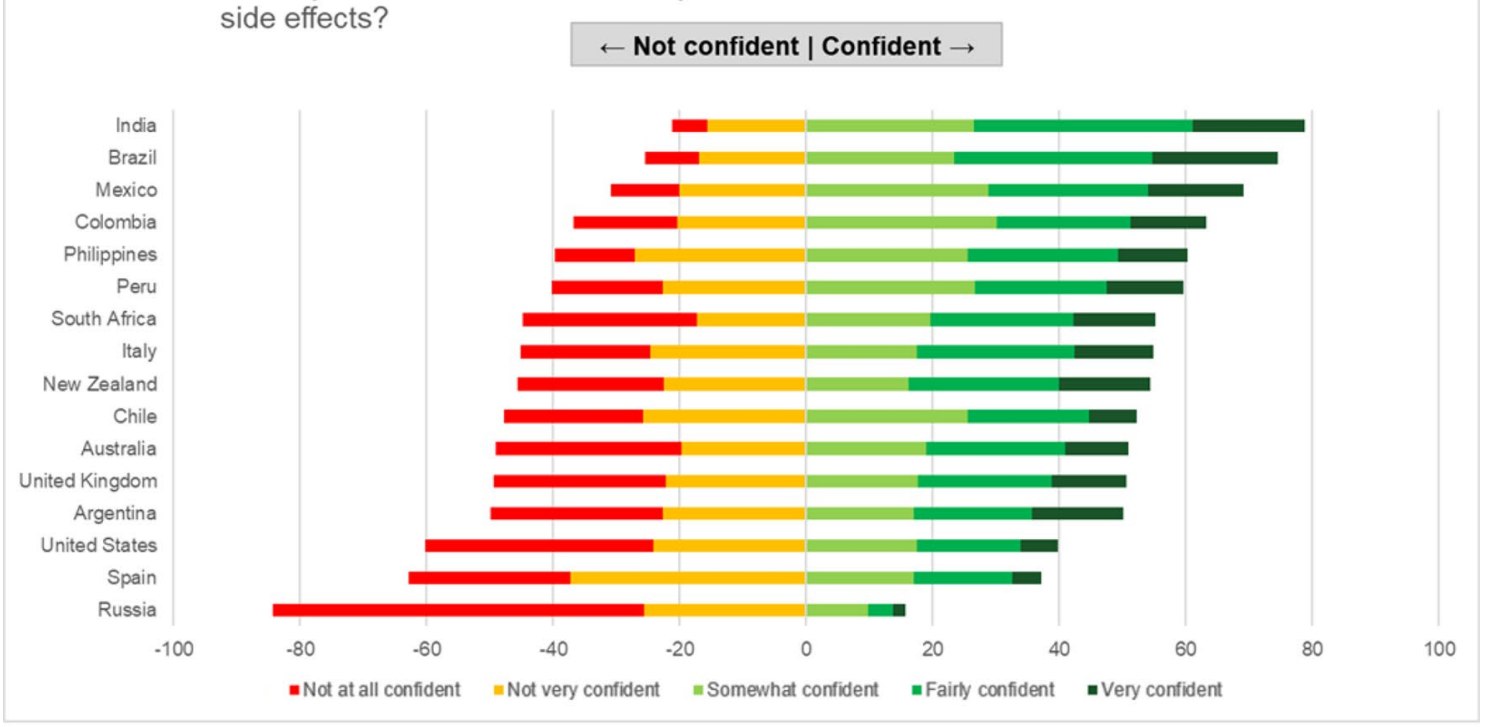

(b) Confidence that the COVID-19 vaccine approved will be effective $(n=17780)$

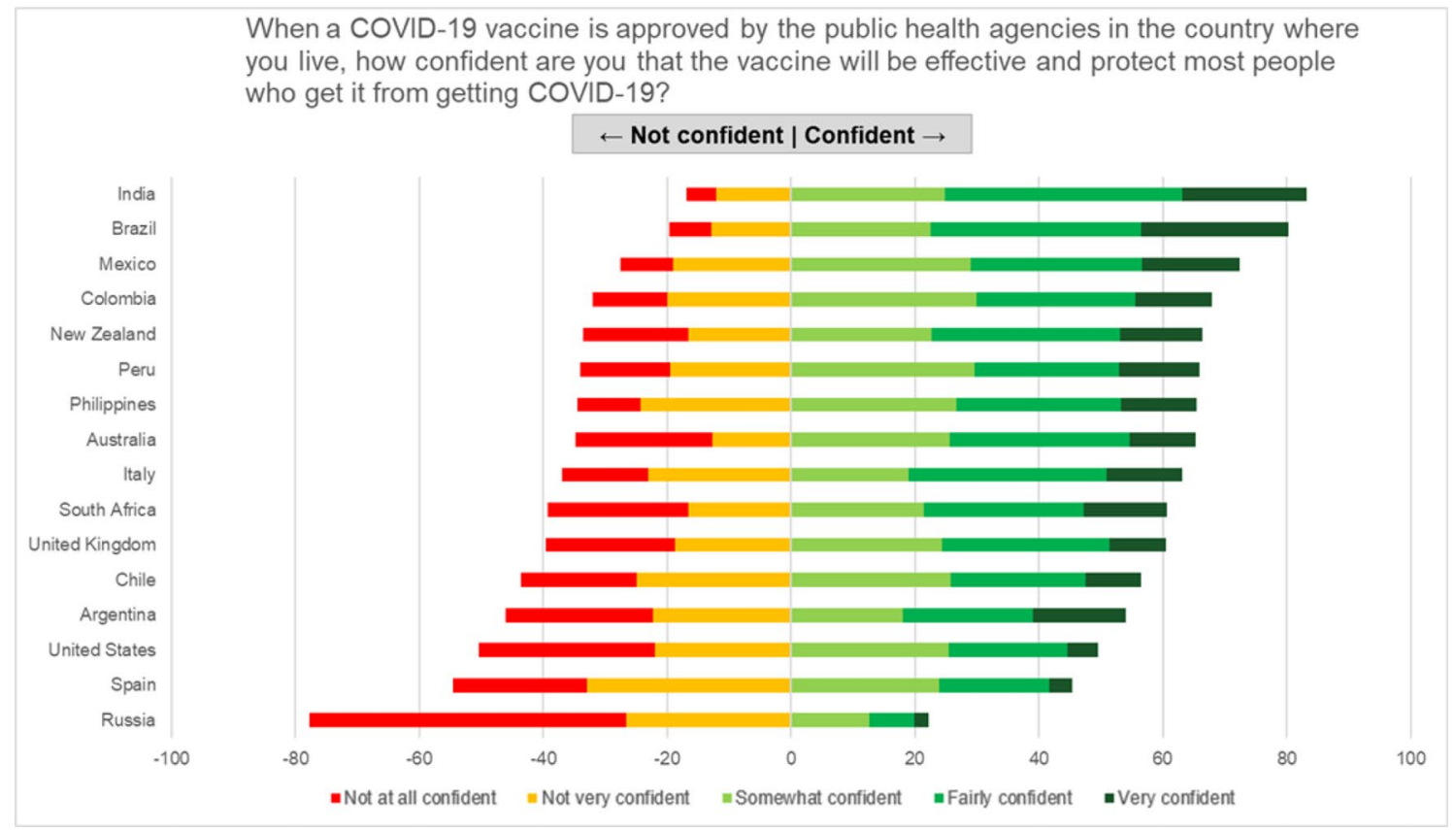

Fig. 3 COVID-19 vaccine confidence markers among pregnant women and mothers of young children. a Confidence that the COVID-19 vaccine approved will be safe $(n=17,790)$. b Confidence that the COVID-19 vaccine approved will be effective $(n=17,780)$

similar for pregnant and non-pregnant women, for selfvaccination and for child vaccination acceptance. The AUC was $0.84,0.94$ and 0.92 for the models of pregnant women, non-pregnant women self-vaccination and child vaccination acceptance, respectively.

These findings persist in all within-country analyses (Table $2 \mathrm{~S}$ ), so we present the pooled analysis only. The correlation between the top predictors and vaccine acceptance found at the individual level is also reflected at the 
(a) Worries about COVID-19 $(n=17844)$

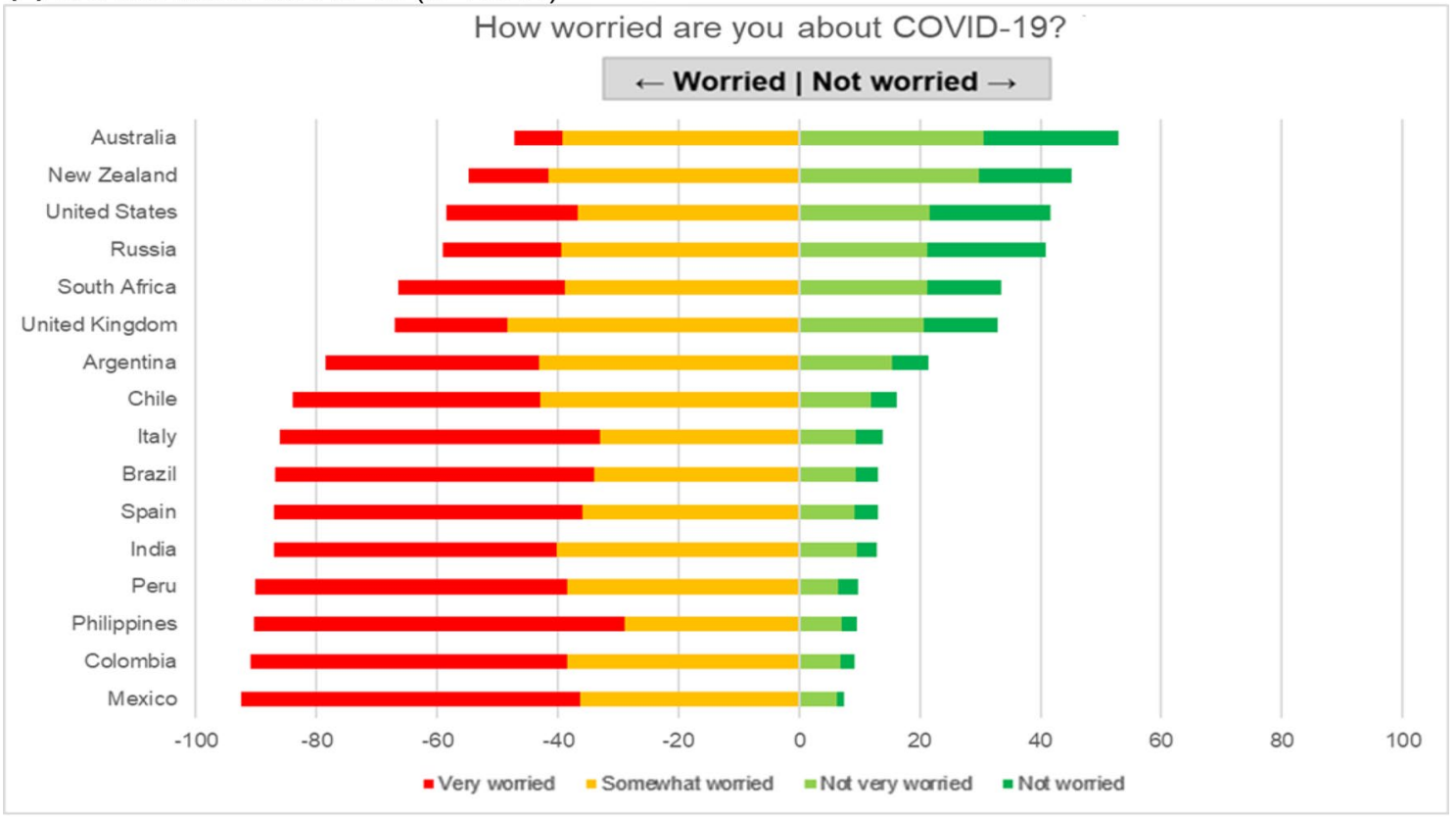

(b) Mask-wearing compliance $(n=17803)$

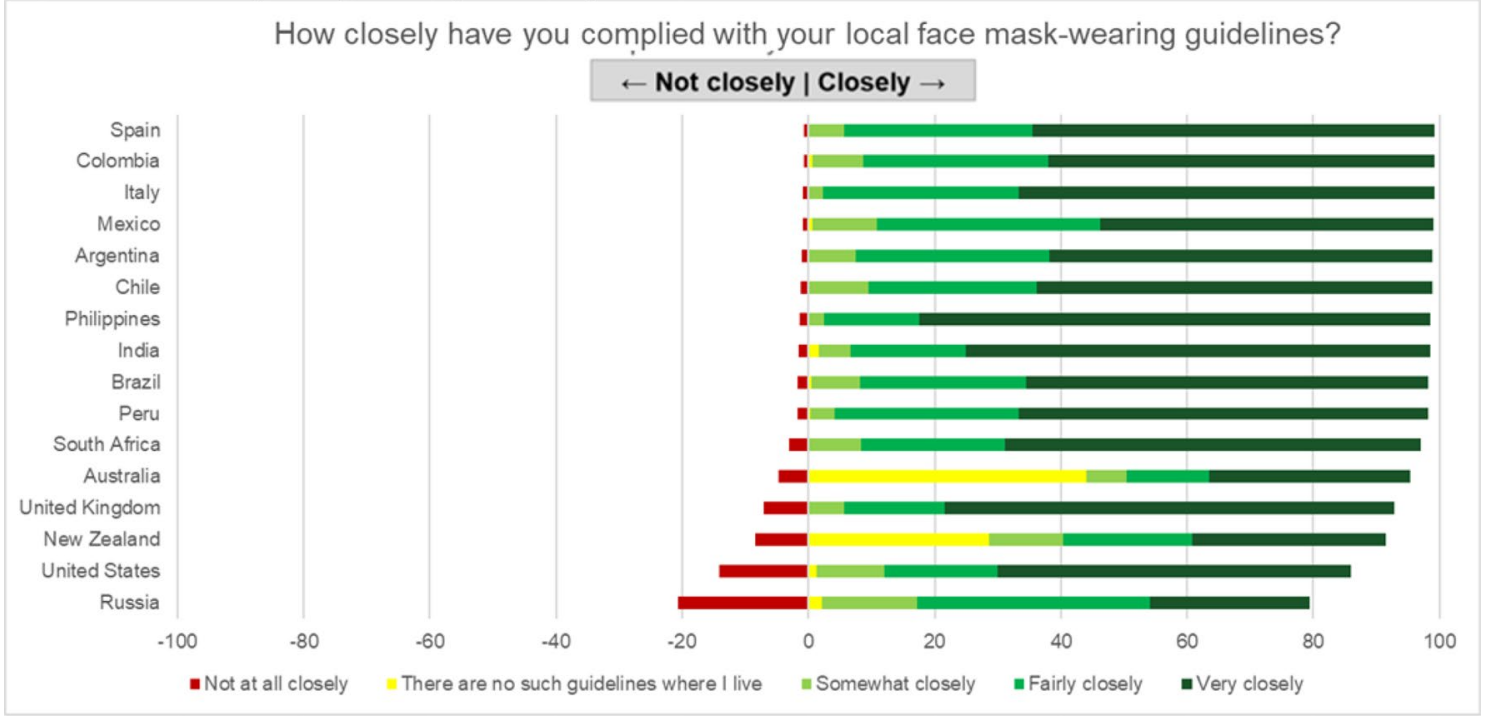

Fig. 4 Perceptions of COVID-19 among pregnant women and mothers of school-aged children. a Worries about COVID-19 ( $\mathrm{n}=17,844)$. b Mask-wearing compliance $(n=17,803)$

ecologic level (e.g., countries with higher trust in public health agencies tend to have higher acceptance).

\section{Interpretations}

We found substantial geographic variation in the acceptance of COVID-19 vaccination among pregnant women and mothers of young. Acceptance in India, the Philippines, and Latin America was above $60 \%$ among pregnant women and above $78 \%$ among non-pregnant women for themselves; and above $75 \%$ among mothers for their children. This is in contrast to women in the US and Russia, who consistently expressed lower acceptance, confidence in COVID19 vaccine safety/effectiveness, perceived importance of COVID-19 vaccination as well as public trust. Confidence in beneficial vaccine outcomes and trust of public health agencies was particularly low in Russia, compared to the other 15 countries in this study. Women's risk perception of COVID-19 in the US and Russia, two countries, was 
(a) Trust that public health agencies would provide accurate vaccine safety information $(n=17839)$

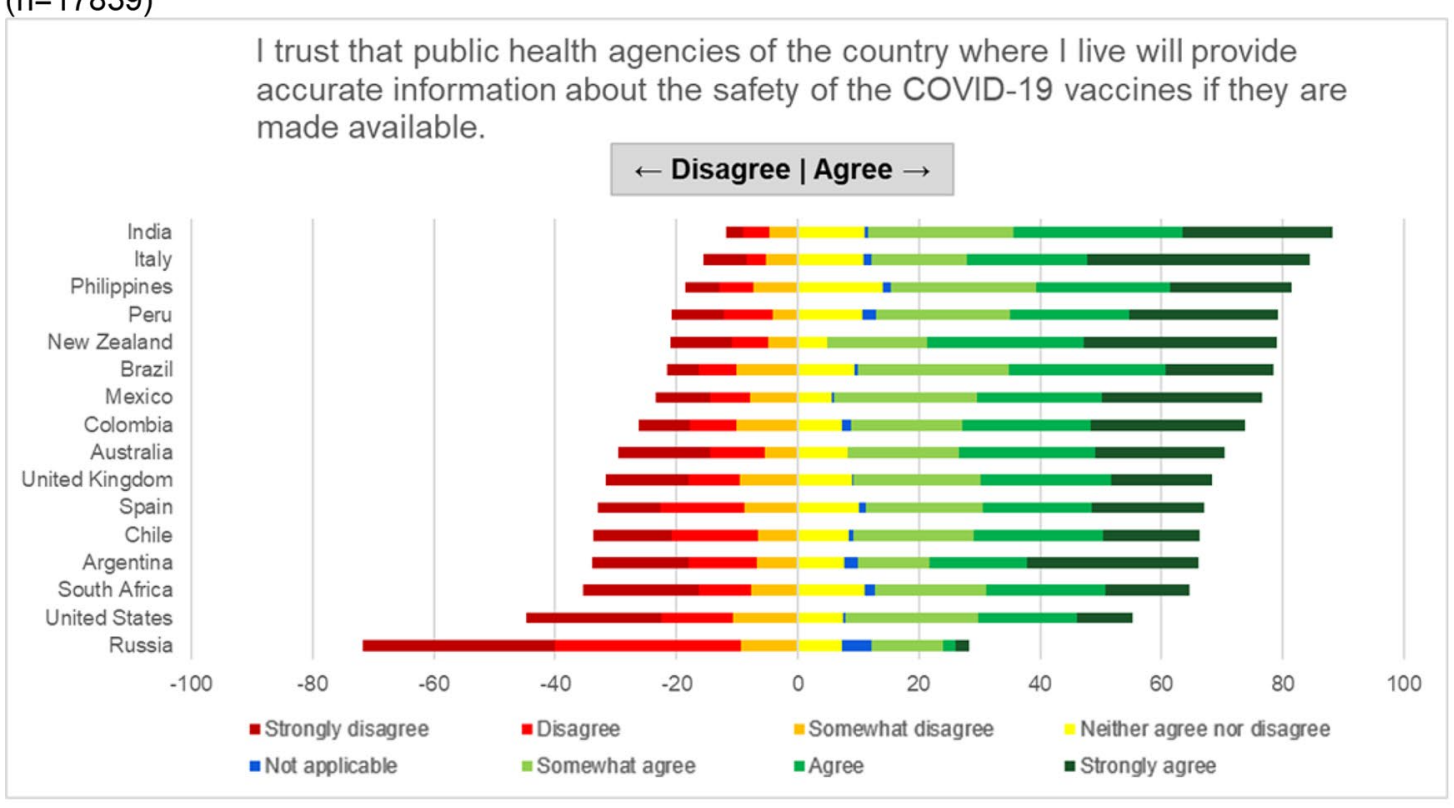

(b) Satisfaction on responsiveness of government policies to participants concerns during the COVID-19 pandemic $(n=17838)$

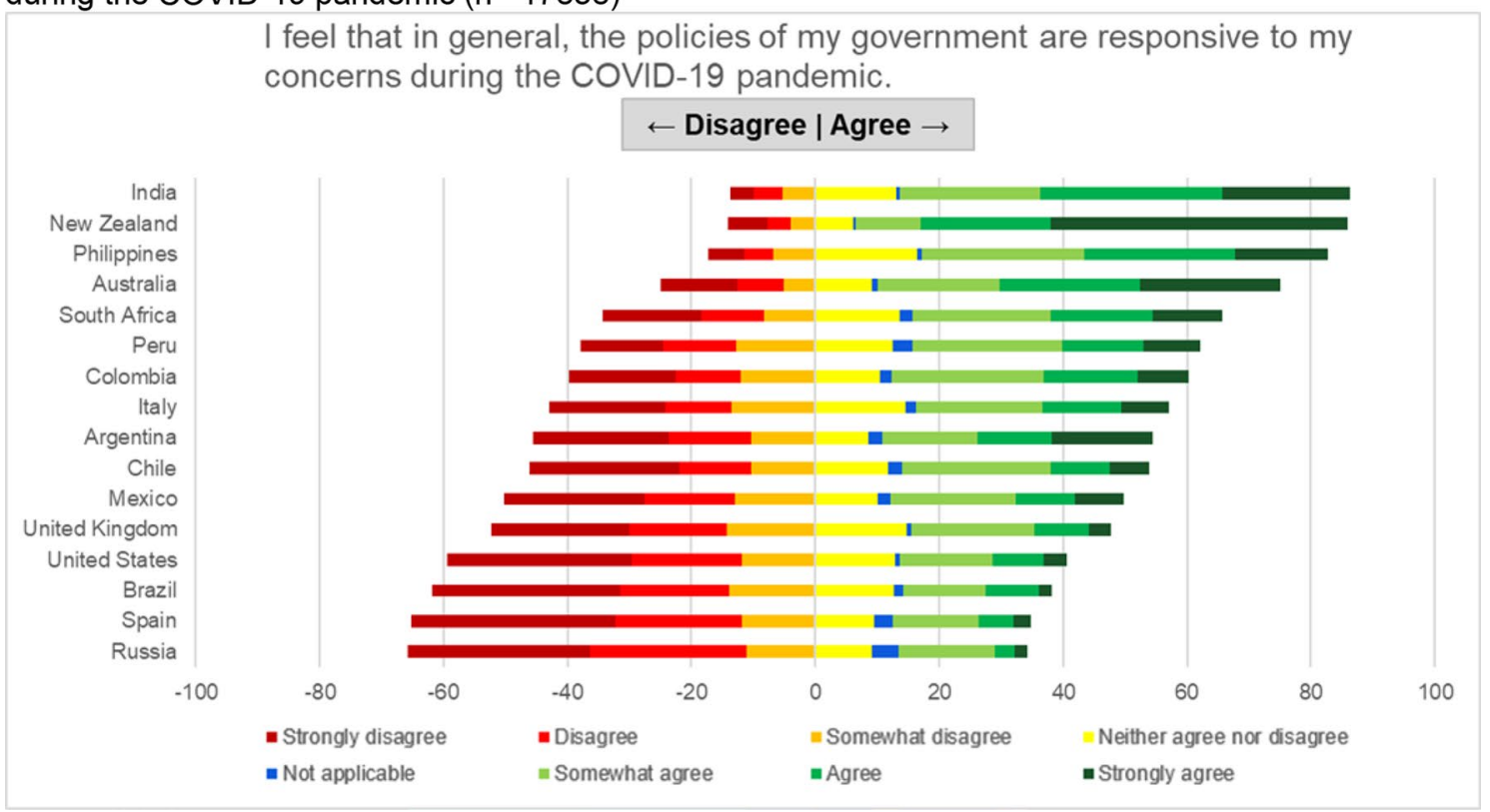

Fig. 5 Public trust and satisfaction among pregnant women and mothers of school-aged children. a Trust that public health agencies would provide accurate vaccine safety information $(n=17,839)$. b

comparable to that in low incidence countries (i.e. Australia and New Zealand), potentially suggesting a phenomenon of COVID-19 denial. These results underscore that a high burden of disease alone may not provide sufficient motivation for pregnant women and mothers of young children to seek vaccination for themselves or their children.
Satisfaction on responsiveness of government policies to participants concerns during the COVID-19 pandemic $(n=17,838)$

Country-level observations were largely confirmed with within-country analysis of individual responses. The strongest predictors of COVID-19 vaccine acceptance were confidence in COVID-19 vaccine safety and effectiveness, belief in the importance of vaccines/mass vaccination to their own country, confidence in routine childhood vaccines, worry about COVID-19, trust of public 
Table 2 Univariate analysis for predictors of COVID-19 vaccine acceptance among pregnant women and mothers of young children

Univariate analysis for acceptance of COVID-19 vaccine with $\geq 90 \% \quad$ Accept for themselves efficacy (likely vs. unlikely)

Characteristics

Age (ref: 40-65 years)

$18-24$

$25-29$

30-34

35-39

Married (ref: unmarried)

Number of children (ref: no child)

One child (used as ref for non-pregnant women only)

Two children

Three or more children

Education (ref: college diploma or equivalent)

$<$ High school

High school or GED

Some college or university

Master's, professional school, doctoral degree

Socioeconomic status (SES)

Middle class to wealthy (ref: lower middle class to poor)

Essential workers (ref: non-essential workers)

Physicians

Nurses

Other health workers

Other essential workers (not health sector)

Health status/insurance

Have health insurance (ref: no health insurance)

At least 1 underlying condition (ref: no underlying condition)

Tested positive for COVID-19 (no COVID-19 test/ tested negative)

Negative experiences with COVID-19

Negatively affected by COVID-19 in any way (ref: not affected)

Suffered complications/disability due to COVID-19 disease (ref: no complications/disability)

Lost a loved one to COVID-19 (ref: no loss)

Other non-COVID-19 related health problems (ref: no additional health problems)

Socially affected by COVID-19/restrictions (ref: not affected)

Financial/job loss (ref: no loss)

Past acceptance and perceived safety/efficacy of other vaccines

Routine immunization for children (ref: no)

Think childhood vaccines are safe (ref: not safe)

Think childhood vaccines are effective in protecting against diseases (ref: not effective)

Received flu vaccination last year or could not receive because of cost or availability (ref: did not receive for reasons other than cost or availability)

Confidence in COVID-19 vaccine

Confident in safety of COVID-19 vaccine post-approval by country's health agencies (ref: not confident)
Accept for child/children

\begin{tabular}{llll}
\hline $\begin{array}{l}\text { Pregnant women } \\
\mathrm{N}=5282\end{array}$ & $\begin{array}{l}\text { Non-pregnant mothers } \\
\text { Odl mothers } \mathrm{N}=17,054\end{array}$ & \\
\cline { 1 - 1 } Odds ratios $95 \% \mathrm{CI}$ & & Odds ratios $95 \% \mathrm{CI}$ & \\
Odds ratios 95\% CI
\end{tabular}

0.80

0.88

0.93

0.92

0.92

0.86

0.57

0.43

0.76

1.25

0.93

1.26

0.92

2.26

0.71

0.78

0.83

0.93

1.21

1.04

1.31

1.97

2.82

1.43

1.27

1.16

8.04

30.7

40.1

3.29

$0.81,1.08 \quad 1.12$

$1.08,1.35 \quad 1.40$

$0.93,1.17 \quad 1.26$

$1.18,1.47 \quad 1.32$

$0.85,4.57 \quad 2.47$

$2.03,3.94 \quad 2.55$

$1.21,1.68 \quad 1.37$

$1.13,1.42 \quad 1.26$

$1.02,1.31 \quad 1.11$

6.46, $10.0 \quad 21.2$

$19.8,47.7 \quad 44.6$

$22.5,71.3 \quad 48.1$

$2.91,3.72 \quad 5.24$

8.42

$7.44,9.53 \quad 40.8$
$0.55,0.79 \quad 0.58$

$0.70,0.89 \quad 0.71$

$0.85,1.05 \quad 0.84$

$0.83,1.03 \quad 0.86$

$1.01,1.19 \quad 1.03$

NA $\quad 0.91$

$0.72,0.86 \quad 0.80$

$0.42,0.52 \quad 0.50$

$0.82,1.14 \quad 0.88$

$0.80,1.02 \quad 0.96$

$0.76,0.95 \quad 0.85$

$1.45,1.81 \quad 1.54$

$1.16,1.36 \quad 1.14$

$1.58,3.56 \quad 2.03$

$0.69,1.03 \quad 0.75$

$0.64,0.90 \quad 0.78$

$0.75,0.94 \quad 0.85$

$1.02,1.22 \quad 1.10$

$1.29,1.52 \quad 1.39$

$1.15,1.38 \quad 1.19$

$1.22,1.43 \quad 1.31$

$1.64,3.74 \quad 2.14$

$2.07,3.13 \quad 2.63$

$1.17,1.37 \quad 1.26$

$1.02,1.20 \quad 1.11$

$18.1,24.9 \quad 19.2$

36.4, $54.6 \quad 46.8$

$37.9,61.0 \quad 52.5$

$38.5,56.8$

$41.5,66.4$

$4.81,5.71 \quad 4.62$

$4.31,4.95$

$0.65,0.88$

$0.69,0.89$

$0.78,0.94$

$1.02,1.18$

$1.30,1.49$

$1.10,1.28$

$1.23,1.40$

$1.51,3.03$

$2.20,3.14$

$1.31,1.54$

$1.18,1.34$

$1.04,1.19$

$16.7,22.0$
$1.25,1.50 \quad 1.42$

$35.1,47.5 \quad 27.8$

$25.0,30.8$ 
Table 2 (continued)

\begin{tabular}{|c|c|c|c|c|c|c|}
\hline \multirow{3}{*}{$\begin{array}{l}\text { Univariate analysis for acceptance of COVID-19 vaccine with } \geq 90 \% \\
\text { efficacy (likely vs. unlikely) } \\
\text { Characteristics }\end{array}$} & \multicolumn{4}{|c|}{ Accept for themselves } & \multirow{2}{*}{\multicolumn{2}{|c|}{$\begin{array}{l}\begin{array}{l}\text { Accept for child/chil- } \\
\text { dren }\end{array} \\
\text { All mothers } N=17,054\end{array}$}} \\
\hline & \multicolumn{2}{|c|}{$\begin{array}{l}\text { Pregnant women } \\
\mathrm{N}=5282\end{array}$} & \multicolumn{2}{|c|}{$\begin{array}{l}\text { Non-pregnant mothers } \\
\mathrm{N}=12,562\end{array}$} & & \\
\hline & Odds ratios & $95 \% \mathrm{CI}$ & Odds ratios & $95 \% \mathrm{CI}$ & Odds ratios & $95 \% \mathrm{CI}$ \\
\hline $\begin{array}{l}\text { Confident in COVID-19 vaccine efficacy post approval by country's } \\
\text { health agencies (ref: not confident) }\end{array}$ & 6.68 & $5.90,7.56$ & 28.1 & $24.9,35.6$ & 19.7 & $18.1,21.5$ \\
\hline \multicolumn{7}{|l|}{ Perceived risk of the virus/precautions } \\
\hline Likely to get COVID-19 (ref: unlikely) & 1.45 & $1.29,1.62$ & 2.02 & $1.86,2.19$ & 1.80 & $1.68,1.92$ \\
\hline Likely for child to be infected with COVID-19 (ref: unlikely) & 1.65 & $1.42,1.93$ & 1.88 & $1.73,2.03$ & 1.87 & $1.74,2.00$ \\
\hline $\begin{array}{l}\text { Likely to develop severe symptoms if COVID-19 is contracted (ref: } \\
\text { unlikely) }\end{array}$ & 2.18 & $1.95,2.43$ & 2.97 & $2.73,3.23$ & 2.91 & $2.72,3.12$ \\
\hline Worried about COVID-19 (ref: not worried) & 5.49 & $4.80,6.28$ & 12.2 & $11.1,13.4$ & 9.99 & $9.24,10.8$ \\
\hline Important for country to have vaccine (ref: not important) & 24.1 & $17.7,32.7$ & 46.4 & $39.4,54.7$ & 45.0 & $38.7,52.4$ \\
\hline $\begin{array}{l}\text { Important for the majority of people in their country getting vac- } \\
\text { cinated (ref: not important) }\end{array}$ & 28.7 & $21.3,38.6$ & 52.0 & $45.0,60.2$ & 53.3 & $46.4,61.2$ \\
\hline Closely complied with mask guidelines (ref: did not comply) & 13.7 & $9.23,20.5$ & 30.5 & $23.9,39.0$ & 24.9 & $20.2,30.6$ \\
\hline $\begin{array}{l}\text { Monitoring COVID-19 news on any media once or less per day } \\
\text { (ref: never) }\end{array}$ & 3.56 & $2.88,4.41$ & 6.27 & $5.49,7.17$ & 5.91 & $5.26,6.63$ \\
\hline \multicolumn{7}{|l|}{ Public trust and satisfaction } \\
\hline Trust in $\mathrm{PH}$ agencies (ref: no trust in $\mathrm{PH}$ agencies) & 4.47 & $3.97,5.03$ & 13.2 & $11.9,14.6$ & 10.7 & $9.86,11.5$ \\
\hline $\begin{array}{l}\text { Satisfied with the country's political leadership on COVID-19 } \\
\text { control (ref: dissatisfied with political leadership) }\end{array}$ & 1.08 & $0.96,1.21$ & 2.63 & $2.41,2.89$ & 2.13 & $1.98,2.30$ \\
\hline Trust in science (ref: no trust in science) & 4.43 & $3.81,5.15$ & 7.91 & $7.21,8.68$ & 7.23 & $6.68,7.83$ \\
\hline Increased trust in science (ref: no increased trust in science) & 3.94 & $3.50,4.44$ & 9.11 & $8.21,10.1$ & 7.42 & $6.85,8.04$ \\
\hline $\begin{array}{l}\text { Satisfied with health authorities (ref: dissatisfied with health } \\
\text { authorities) }\end{array}$ & 1.68 & $1.50,1.87$ & 3.66 & $3.35,4.01$ & 3.06 & $2.85,3.29$ \\
\hline $\begin{array}{l}\text { Satisfied with political response (ref: dissatisfied with political } \\
\text { response) }\end{array}$ & 1.62 & $1.44,1.81$ & 4.00 & $3.64,4.40$ & 3.32 & $3.08,3.58$ \\
\hline
\end{tabular}

health agencies and science, as well as compliance with face mask-wearing guidelines. Although this may suggest overlap in general vaccine confidence, it should be noted that skepticism of COVID-19 vaccine safety and effectiveness was far greater within all countries. The International Registry of Coronavirus Exposure in Pregnancy (IRCEP) and several safety surveillance systems are underway to collect such information [21]. The results of these efforts may influence several of the significant factors identified here, providing more specific data for these populations, and opportunities to build on trust in the scientific review of such vaccines.

Our findings of the heterogeneous COVID-19 vaccine acceptance level among pregnant women and mothers in different countries are consistent with previous reports from the general population. Polls conducted in the US in July 2020 showed that only $66 \%$ of adults would be likely to vaccinate themselves or their children [10]. In a global survey conducted in June 2020 in 19 countries, $71.5 \%$ of participants stated that they would be likely to get vaccinated for COVID-19, but acceptance levels ranged from $90 \%$ in China to less than $55 \%$ in Russia. A relatively high likelihood of acceptance in middle-income countries, such as Brazil, India and South Africa, was also reported [11]. The higher acceptance among the middle-income countries suggests the role historical burdens of other infectious diseases might play on both the higher perception of risk from COVID-19 and the more positive vaccine attitude.

These results confirmed our hypothesis that COVID-19 vaccine hesitancy is a multifaceted event [22]. Perceived risk of the virus and the disease, as well as public trust, play key roles shaping the vaccine acceptance and confidence on top of the existing pre-COVID 19 vaccine attitudes. Perceived risk of COVID-19 for the population, as measured by worries of COVID-19, belief in importance of having a COVID-19 vaccine and mass vaccination, was a much stronger predictor of COVID-19 vaccine acceptance and confidence in comparison to perceived risk of infection for themselves or their children. Doubt of the disease, skepticism of a new vaccine, distrust of the system, along with previously shaped vaccination belief have interplayed and together contributed to the reluctance we observed. Even 
Table 3 Multivariate analysis for predictors of COVID-19 vaccine acceptance among pregnant women and mothers of young children, with adjustment for all countries

Multivariate analysis for acceptance of covid-19 vaccine with $\geq 90 \%$ efficacy (likely vs. unlikely)

$\begin{array}{ll}\text { Accept for themselves } \\ \begin{array}{l}\text { Pregnant women } \\ \mathrm{N}=5282\end{array} & \begin{array}{l}\text { Non-pregnant Moth- } \\ \text { ers N=12,562 }\end{array} \\ \begin{array}{l}\text { Adjusted 95\% CI } \\ \text { odds ratio }\end{array} & \begin{array}{l}\text { Adjusted 95\% CI } \\ \text { odds ratio }\end{array}\end{array}$

Accept for child/ children

All mothers $\mathrm{N}=17,054$

Adjusted 95\% CI odds ratio

\begin{tabular}{|c|c|c|c|c|c|c|c|c|c|}
\hline \multicolumn{10}{|l|}{ Age (ref 40-65 years) } \\
\hline $18-24$ & 1.20 & 0.73 & 1.99 & 0.93 & 0.67 & 1.28 & 0.96 & 0.75 & 1.22 \\
\hline $25-29$ & 1.04 & 0.66 & 1.66 & 0.92 & 0.74 & 1.14 & 0.83 & 0.70 & 0.99 \\
\hline $30-34$ & 0.90 & 0.57 & 1.42 & 1.02 & 0.85 & 1.22 & 0.86 & 0.74 & 1.00 \\
\hline $35-39$ & 0.83 & 0.52 & 1.33 & 1.02 & 0.85 & 1.22 & 0.85 & 0.73 & 0.99 \\
\hline \multicolumn{10}{|l|}{ Marital status } \\
\hline Married (ref: not married) & 1.03 & 0.86 & 1.23 & 1.03 & 0.89 & 1.20 & 0.96 & 0.85 & 1.08 \\
\hline \multicolumn{10}{|l|}{ Number of children (ref: no children) } \\
\hline One child (used as ref for non-pregnant women only) & 1.02 & 0.87 & 1.20 & NA & NA & NA & 0.90 & 076 & 1.08 \\
\hline Two children & 0.92 & 0.72 & 1.18 & 0.94 & 0.81 & 1.10 & 1.00 & 0.82 & 1.20 \\
\hline Three or more children & 1.12 & 0.77 & 1.63 & 0.78 & 0.64 & 0.94 & 0.92 & 0.74 & 1.15 \\
\hline \multicolumn{10}{|l|}{ Education (ref: college diploma or university degree) } \\
\hline$<$ High school & 0.86 & 0.58 & 1.28 & 1.03 & 0.78 & 1.36 & 0.85 & 0.68 & 1.07 \\
\hline High school or GED & 1.36 & 1.01 & 1.82 & 0.86 & 0.69 & 1.06 & 0.93 & 0.78 & 1.12 \\
\hline Some college or university & 1.11 & 0.89 & 1.39 & 0.98 & 0.81 & 1.18 & 1.04 & 0.89 & 1.21 \\
\hline Master's, professional school, doctoral degree & 0.79 & 0.66 & 0.94 & 1.01 & 0.84 & 1.21 & 0.90 & 0.79 & 1.04 \\
\hline \multicolumn{10}{|l|}{ Essential worker (ref: not an essential worker) } \\
\hline Worked as a physician & 1.48 & 0.93 & 2.35 & 0.88 & 0.47 & 1.63 & 0.73 & 0.49 & 1.10 \\
\hline Worked as a nurse & 0.69 & 0.52 & 0.91 & 0.75 & 0.54 & 1.04 & 0.71 & 0.56 & 0.90 \\
\hline Worked in another health-related sector & 0.79 & 0.62 & 1.00 & 0.84 & 0.62 & 1.12 & 0.80 & 0.65 & 0.99 \\
\hline Worked as another essential worker & 0.99 & 0.81 & 1.21 & 1.00 & 0.83 & 1.20 & 1.05 & 0.90 & 1.21 \\
\hline \multicolumn{10}{|l|}{ Socioeconomic status (SES) } \\
\hline Middle class to wealthy (ref: lower middle class to poor) & 0.84 & 0.71 & 0.99 & 1.03 & 0.89 & 1.19 & 0.84 & 0.75 & 0.94 \\
\hline \multicolumn{10}{|l|}{ Insurance } \\
\hline Insured (ref: uninsured) & 0.95 & 0.77 & 1.18 & 1.20 & 1.03 & 1.41 & 1.22 & 1.07 & 1.39 \\
\hline \multicolumn{10}{|l|}{ Past acceptance and perceived safety/efficacy of other vaccines } \\
\hline Routine immunization for children (ref: no) & 1.75 & 1.27 & 2.41 & 2.26 & 1.68 & 3.05 & 2.42 & 1.90 & 3.08 \\
\hline Think childhood vaccines are safe (ref: not safe) & 2.09 & 1.11 & 3.95 & 2.42 & 1.74 & 3.38 & 2.27 & 1.67 & 3.08 \\
\hline $\begin{array}{l}\text { Thinks childhood vaccines are effective in protecting against diseases } \\
\text { (ref: not effective) }\end{array}$ & 1.57 & 0.69 & 3.58 & 1.48 & 1.01 & 2.18 & 1.39 & 0.97 & 1.99 \\
\hline Did receive flu vaccination last year (ref: did not receive) & 1.40 & 1.18 & 1.67 & 1.58 & 1.36 & 1.82 & 1.45 & 1.29 & 1.63 \\
\hline \multicolumn{10}{|l|}{ Confidence in COVID-19 vaccine } \\
\hline $\begin{array}{l}\text { Confident in safety of COVID-19 vaccine post-approval by country's } \\
\text { health agencies (ref: not confident) }\end{array}$ & 3.68 & 3.02 & 4.50 & 5.12 & 4.06 & 6.46 & 4.97 & 4.23 & 5.84 \\
\hline $\begin{array}{l}\text { Confident in COVID-19 vaccine efficacy post approval by country's } \\
\text { health agencies (ref: not confident) }\end{array}$ & 1.26 & 1.02 & 1.55 & 2.35 & 1.93 & 2.87 & 2.03 & 1.76 & 2.35 \\
\hline \multicolumn{10}{|l|}{ Perceived risk of the virus/precautions } \\
\hline Worried about COVID-19 (ref: not worried) & 1.79 & 1.48 & 2.16 & 2.47 & 2.11 & 2.90 & 1.99 & 1.75 & 2.26 \\
\hline Important for country to have vaccine (ref: not important) & 1.74 & 1.05 & 2.87 & 1.68 & 1.25 & 2.25 & 1.60 & 1.22 & 2.09 \\
\hline $\begin{array}{l}\text { Important for the majority of people in their country getting vac- } \\
\text { cinated (ref: not important) }\end{array}$ & 3.08 & 1.95 & 4.85 & 4.46 & 3.50 & 5.68 & 4.89 & 3.91 & 6.12 \\
\hline Closely complied with mask guidelines (ref: did not closely comply) & 1.10 & 0.65 & 1.89 & 2.69 & 1.80 & 4.04 & 1.85 & 1.32 & 2.57 \\
\hline \multicolumn{10}{|l|}{ Monitoring COVID-19 news on any media } \\
\hline Monitors COVID-19 news at least $1 \times$ a day (ref: never monitors) & 1.17 & 0.86 & 1.59 & 1.06 & 0.83 & 1.35 & 1.21 & 0.99 & 1.48 \\
\hline
\end{tabular}


Table 3 (continued)

Multivariate analysis for acceptance of covid-19 vaccine with $\geq 90 \%$ efficacy (likely vs. unlikely)

Accept for themselves

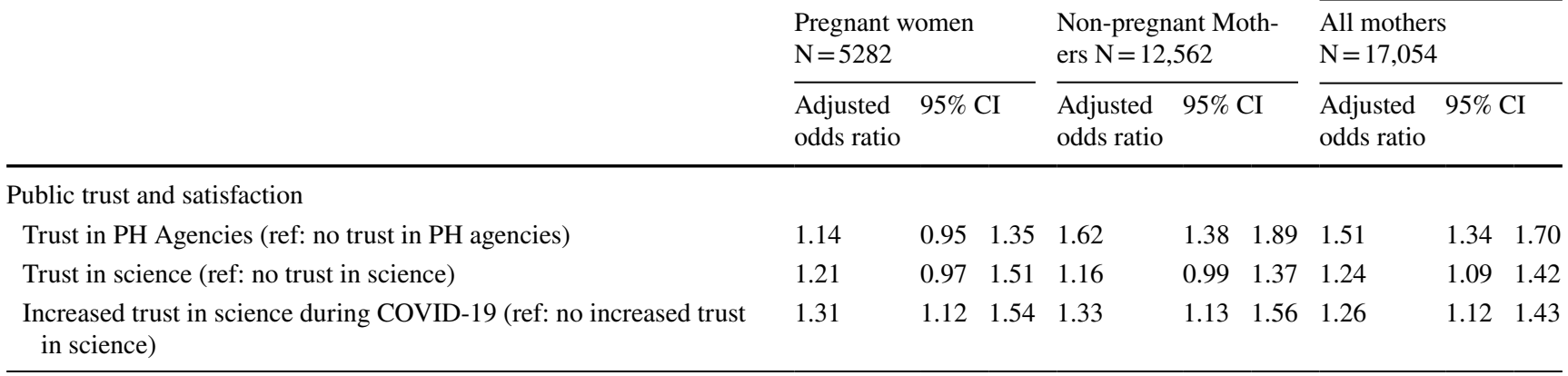

Accept for child/ children

All mothers $\mathrm{N}=17,054$ though these parameters are dynamic and being influenced by current events in this pandemic, their roles do seem to follow what we have known in the past regarding the general factors for vaccine hesitancy [22-26].

Our findings suggest that there is room for governments, especially those of countries currently experiencing COVID19 denial and public distrust to rebuild confidence in the coming months as vaccine roll-out continues. Policy makers must address such denial and doubt of the disease, public fears and misconception using clear and unified communication to create a national consensus of the utter importance of public health measures including face mask-wearing and mass vaccination to end this pandemic crisis. The public risk perception and confidence of a new vaccine can thus be put into perspectives of what is truly at stake. Health providers' recommendation alone will have limited effects on improving acceptance among this population. For those who do not follow COVID-19 news through any media and have high vaccine reluctance, alternative communication methods are needed. Lessons learned from previous new vaccine roll-out including human papillomavirus (HPV) vaccine roll-out and Ebola vaccine trial field experiences have all underscored the importance of community work with sensitivity toward country-, local- and subgroup- specific culture contexts [27, 28]. Significant portions of pregnant women and mothers expressed additional safety concerns due to insufficient pregnancy- and children- related clinical evidence. As more such data become available for these two groups, there will be more opportunities for pregnant women and mothers to build trust on the scientific approval of these vaccines.

This survey captured rich data in a large study population from a wide span of COVID-19-affected countries on the topics of vaccine acceptance and its predictors. Findings provide important information that can be used for evidence-based policy making to ultimately enhance vaccination of vulnerable populations such as pregnant women and children. However, there are several study limitations to note. Although the survey encompasses responses from 16 countries and was available in six languages, the responses may not be generalizable to other regions. However, the consistency among the 16 geographically disperse countries strongly suggest that predictors are likely to be universal. Selection bias is a possibility as participants had an overall higher education level than the general public and were predominantly white in the US and European countries. Furthermore, as the survey was conducted online, study participants were limited to those who had access to the technology and resources to participate in the survey. This limitation could have prevented vaccine acceptance levels captured from the most vulnerable groups with generally higher than average levels of vaccine hesitancy and caused an overall overestimation of the acceptance. The overall sample was not probability-weighted based on each country's population size, and therefore results should not be viewed as weightedaverage estimates from all the 16 countries' populations of women of child-bearing age. Our intention was rather to understand the most important predictors and the underlying interplay between the factors and to draw key insights for global policymakers. Like all online surveys, responses differ based on the respondent's personal attitudes, feelings, and inherent biases, and are therefore a snapshot of the vaccine acceptance in time of a highly dynamic and evolving landscape in these countries. Vaccine acceptance levels might change over the course of time, especially as vaccine education campaigns begin in these countries.

In the two months since this study was conducted, several important events have occurred: an alarming surge in new coronavirus infections and deaths worldwide, the authorization of several COVID-19 vaccines, with messenger ribonucleic acid (mRNA) vaccines achieving efficacies as high as $95 \%$, and the initiation of vaccination campaigns with millions of doses being administered globally [1, 4-6, 29].These developments will likely impact the key predictors such as COVID-19 risk perception, confidence in the COVID-19 vaccine and public trust and may improve public acceptance, as suggested by more recent national 
surveys in the US [30]. As global vaccine rollouts continue, monitoring acceptance and its predictors will provide policymakers with key insights to understand public willingness and make informed policies that are effective. It is especially urgent for countries currently experiencing widespread public distrust during the pandemic to rebuild vaccine confidence through transparent communication and effective community engagement. COVID-19 vaccine education campaigns need to emphasize the pandemic as a whole and what's at stake for communities, instead of a limited focus of vaccine safety and effectiveness. As more specific data for these vulnerable groups become available, it will provide opportunities to influence key predictors we identified and enhance public trust in the rigorous approval of upcoming vaccines [21].

Current acceptance levels of a COVID-19 vaccine among most of the high-income countries included in this study are insufficient to meet the requirements for community immunity of at least $75 \%$. COVID-19 vaccine acceptance and its predictors among pregnant women and mothers of young children vary globally and, therefore, vaccination campaigns for this population should be specified for each country in order to attain the largest impact.

Supplementary Information The online version contains supplementary material available at https://doi.org/10.1007/s10654-021-00728-6.

Acknowledgements We thank Harpreet "Harry" and Gurpreet Singh for the many hours spent developing the survey platform and all the study participants for their trust, time and efforts contributing to the study. We appreciate all the valuable discussions with our colleagues.

Author contributions JWW, DFW and SHD conceived and designed the study. JWW created the survey tool, oversaw the study conduct and analysis. DFW was responsible for the Pregistry online platform operation and participants' enrollment. MS, MN and OA performed data quality control, conducted the statistical analyses and created key tables and figures. JWW, DFW and SHD contributed to creation of key tables and figures. MS, MN, JWW, DE, and DFW drafted the first version of the manuscript. All authors contributed intellectually to data interpretation, finalized and approved the manuscript for publication. JWW and DFW secured funding for the study.

Funding This study was funded jointly funded by the Human Immunomics Initiative at the Harvard TH Chan School of Public Health and Pregistry, LLC.

Data availability Data for this study will be made available to others in the scientific community upon request one year after the publication of this article. Standard criteria for making data available for valid research projects will be used, following application by suitably qualified researchers. For data access, please contact Pregistry at hello@ pregistry.com

Code availability The code for this study will be made available to others in the scientific community upon request one year after the publication of this article. Standard criteria for making the code available for valid research projects will be used, following application by suitably qualified researchers. For code access, please contact Julia Wu.

\section{Compliance with ethical standards}

Conflict of interest The authors disclose no potential conflicts of interest or competing interests.

Ethics approval The study was classified exempt by the Harvard Longwood Campus Institutional Review Board (HLC IRB) per the regulations found at 45 CFR 46.104(d)(2) on the basis that it poses no greater than minimal risk and that the recorded information cannot readily identify the subject (directly or indirectly). The study protocol was reviewed and approved by the ethical review committee of Harvard Longwood Campus.

Consent to participate All study participants provided their informed consent to participate in the study before completing the survey.

Consent for publication All contributing authors provided their consent for publication.

Open Access This article is licensed under a Creative Commons Attribution 4.0 International License, which permits use, sharing, adaptation, distribution and reproduction in any medium or format, as long as you give appropriate credit to the original author(s) and the source, provide a link to the Creative Commons licence, and indicate if changes were made. The images or other third party material in this article are included in the article's Creative Commons licence, unless indicated otherwise in a credit line to the material. If material is not included in the article's Creative Commons licence and your intended use is not permitted by statutory regulation or exceeds the permitted use, you will need to obtain permission directly from the copyright holder. To view a copy of this licence, visit http://creativecommons.org/licenses/by/4.0/.

\section{References}

1. Johns Hopkins Coronavirus Resource Center. COVID-19 dashboard. https://coronavirus.jhu.edu/map.html. Accessed 26 Dec 26 2020.

2. World Bank. COVID-19 to add as many as 150 million extreme poor by 2021 World Bank. https://www.worldbank.org/en/news/ press-release/2020/10/07/covid-19-to-add-as-many-as-150-milli on-extreme-poor-by-2021. Accessed 22 Dec 2020.

3. Diseases TLI. The intersection of COVID-19 and mental health. Lancet Infect Dis. 2020;20:1217.

4. Pfizer. Pfizer and BioNTech announce vaccine candidate against COVID-19 achieved success in first interim analysis from phase 3 study. https://www.pfizer.com/news/press-release/press-relea se-detail/pfizer-and-biontech-announce-vaccine-candidate-again st. Accessed 22 Dec 2020.

5. Moderna announces primary efficacy analysis in Phase 3 COVE study for its COVID-19 vaccine candidate and filing today with U.S. FDA for emergency use authorization. https://inves tors.modernatx.com/news-releases/news-release-details/moder na-announces-primary-efficacy-analysis-phase-3-cove-study. Accessed 22 Dec 2020

6. Zimmer C, Corum J, Wee S. Coronavirus vaccine tracker. https ://www.nytimes.com/interactive/2020/science/coronavirus-vacci ne-tracker.html. Accessed 24 Dec 2020.

7. Bloom B, Nowak G, Orenstein W. When will we have a vaccine? Understanding questions and answers about covid-19 vaccination. N Engl J Med. 2020;383:2202-4. 
8. World Health Organization. Ten health issues WHO will tackle this year. https://www.who.int/news-room/spotlight/ten-threatsto-global-health-in-2019. Accessed 22 Dec 2020.

9. SAGE Working Group on Vaccine Hesitancy. Report of the SAGE Working Group on Vaccine Hesitancy. https://www.who.int/ immunization/sage/meetings/2014/october/SAGE_working_group _revised_report_vaccine_hesitancy.pdf. Accessed 22 Dec 2020.

10. Perlis R, Lazer D, Ognayanova K, Druckman BM, Santillana M, et al. State of the nation: a 50-state COVID-19 survey report \#9: Will Americans vaccinate themselves and their children against COVID-19? https://covidstates.org/reports/. Accessed 24 Dec 2020.

11. Lazarus J, Ratzan S, Palayew A, Gostin L, Larson H, Rabin K, et al. A global survey of potential acceptance of a COVID-19 vaccine. Nat Med. 2020;27:1-4.

12. Barello S, Nania T, Dellafiore F, Graffigna G, Caruso R. 'Vaccine hesitancy' among university students in Italy during the COVID19 pandemic. Eur J Epidemiol. 2020;35:781-3.

13. Ellington S, Strid P, Tong V, Woodworth K, Galang R, Zambrano $\mathrm{L}$, et al. Characteristics of women of reproductive age with laboratory-confirmed SARS-CoV-2 infection by pregnancy statusUnited States, January 22-June 7, 2020. MMWR Morb Mortal Wkly Rep. 2020;69:769-75.

14. Collin J, Byström E, Carnahan A, Ahrne M. Public Health Agency of Sweden's brief report: pregnant and postpartum women with severe acute respiratory syndrome coronavirus 2 infection in intensive care in Sweden. Acta Obstet Gynecol Scand. 2020;99:819-22.

15. Delahoy MJ, Whitaker M, O'Halloran A, Chai SJ, Kirley PD, Alden N, et al. Characteristics and maternal and birth outcomes of hospitalized pregnant women with laboratory-confirmed COVID19-COVID-NET, 13 states, March 1-August 22, 2020. MMWR Morb Mortal Wkly Rep. 2020;69:1347-54.

16. Panagiotakopoulos L, Myers TR, Gee J, Lipkind HS, Kharbanda EO, Ryan DS, et al. SARS-CoV-2 infection among hospitalized pregnant women: reasons for admission and pregnancy characteristics-eight US health care centers, March 1-May 30, 2020. MMWR Morb Mortal Wkly Rep. 2020;69:1355-9.

17. Zambrano LD, Ellington S, Strid P, Galang RR, Oduyebo T, Tong VT, et al. Update: characteristics of symptomatic women of reproductive age with laboratory-confirmed SARS-CoV-2 infection by pregnancy status-United States, January 22-October 3, 2020. MMWR Morb Mortal Wkly Rep. 2020;69:1641-7.

18. Mehta NS, Mytton OT, Mullins EW, Fowler TA, Falconer CL, Murphy OB, et al. SARS-CoV-2 (COVID19): What do we know about children? A systematic review. Clin Infect Dis. 2020;71:2469-79.

19. Ludvigsson J. Children are unlikely to be the main drivers of the COVID-19 pandemic - a systematic review. Acta Paediatr. 2020;109:1525-30.
20. Pregistry. International registry of Coronavirus exposure in pregnancy. https://corona.pregistry.com. Accessed 25 Dec 2020.

21. ClinicalTrials.gov [Internet]. Bethesda (MD): national library of medicine (US). 2020 Dec 24 - identifier NCT04366986, international registry of coronavirus (COVID-19) exposure in pregnancy (IRCEP). Available from: https://clinicaltrials.gov/ct2/show/ NCT04366986.

22. Harrison EA, Wu JW. Vaccine confidence in the time of COVID19. Eur J Epidemiol. 2020;35:325-30.

23. Larson H, Cooper L, Eskola J, Katz S, Ratzan S. Addressing the vaccine confidence gap. Lancet. 2011;378:526-35.

24. Dubé E, Laberge C, Guay M, Bramadat P, Roy R, Bettinger J. Vaccine hesitancy: an overview. Hum Vaccin Immunother. 2013;9:1763-73.

25. Larson HJ, Jarrett C, Eckersberger E, Smith DMD, Paterson P. Understanding vaccine hesitancy around vaccines and vaccination from a global perspective: a systematic review of published literature, 2007-2012. Vaccine. 2014;32:2150-9.

26. De Figueiredo A, Simas C, Karafillakis E, Paterson P, Larson HJ. Mapping global trends in vaccine confidence and investigating barriers to vaccine uptake: a large-scale retrospective temporal modelling study. Lancet. 2020;396:898-908.

27. Morimoto A, Ueda Y, Egawa-Takata T, Yagi A, Terai Y, Ohmichi M, et al. Effect on HPV vaccination in Japan resulting from news report of adverse events and suspension of governmental recommendation for HPV vaccination. Int J Clin Oncol. 2015;20:549-55.

28. Dada S, McKay G, Mateus A, Lees S. Lessons learned from engaging communities for Ebola vaccine trials in Sierra Leone: reciprocity, relatability, relationships and respect (the four R's). BMC Public Health. 2019;19:1665.

29. Randall T, Sam C, Tartar A, Cannon C. More than 5.6 million shots given: COVID-19 Vaccine Tracker. https://www.bloom berg.com/graphics/covid-vaccine-tracker-global-distribution/. Accessed 30 Dec 2020.

30. Hamel L, Kirzinger A, Muñana C, Brodie M. KFF COVID-19 vaccine monitor: December 2020. https://www.kff.org/coronaviru s-covid-19/report/kff-covid-19-vaccine-monitor-december-2020/. Accessed 30 Dec 2020

Publisher's Note Springer Nature remains neutral with regard to jurisdictional claims in published maps and institutional affiliations. 